\title{
Reflexión sobre la baja exigencia: una aproximación al trabajo con personas en exclusión residencial grave
}

Pablo Ruiz Errea

Asociación Bizitegi

<pruiz@bizitegi.org>

\section{Patricia Beteta}

Asociación Bizitegi
Bizitegi Elkarteak egin duen artikulu honetan, bizitegi-bazterketa larria pairatzen duten pertsonekin lan egiten duten profesionalen gogoetak, proposamenak eta praktika egokiak bildu ditugu. Exijentzia apala deritzogun testuinguru batean egiten dute lan hori. Bi hitz horiek definitzen dute bai pertsona jakin batzuen profila bai baliabide sail baten karakterizazioa, gizarte-arloan eskuartzeko metodologia zehatz gisa. Esapide baten atzean (exijentzia apala) zer dagoen azaltzen du, gizarte-bazterketaren arloan diharduten pertsonek hitzetik hortzera darabilten esapidea, zeinaren inguruan apenas dagoen gogoeta eta azterlan idatzirik. Beraz, hutsune hori betetzeko ahalegin bat da, funtsezkotzat ditugun gai batzuk aipatu eta definitzekoa.

\section{GAKO-HITZAK:}

Exijentzia apala, gizarte-bazterketa, etxerik gabeko pertsonak, gizarte eskuartzea, Bizitegi Elkartea.
Este artículo elaborado por la Asociación Bizitegi recoge las reflexiones, propuestas y buenas prácticas de profesionales que trabajan atendiendo a personas en situación de exclusión residencial grave en un contexto que denominamos 'baja exigencia'. Este término define tanto un perfil de personas atendidas como la caracterización de una serie de dispositivos y una metodología concreta de intervención social. El artículo explica lo que hay detrás de una expresión (baja exigencia) que está constantemente en boca de las personas que trabajan en contacto con la exclusión social, y de la que apenas hay reflexiones ni estudios escritos. Supone, por lo tanto, un intento por rellenar ese vacío señalando y definiendo algunas cuestiones que consideramos claves.

\section{Palabras clave:}

Baja exigencia, exclusión social, personas sin hogar, intervención social, Asociación Bizitegi. 


\section{Presentación}

En Bizitegi, llevamos desde 1980 atendiendo a personas que, por diferentes motivos, se han encontrado en situación de exclusión social. Lo hemos hecho en distintos barrios de Bilbao (Otxarkoaga, Rekalde, Uribarri, Bilbao Centro) y atendiendo a ciudadanos con diversas problemáticas (económicas, de salud, de soledad). Desde 1999, en colaboración con el Ayuntamiento de Bilbao, trabajamos para atender de manera específica a las personas sin hogar.

El primer objetivo que siempre buscamos al crear o gestionar cualquier dispositivo es que sirva de plataforma para posibilitar procesos de inclusión que desemboquen en una vida autónoma. Sin embargo, el trabajo de todos estos años nos ha ido mostrando que hay multitud de personas en nuestras calles que están muy lejos de esa situación. Su estado es tan precario y sus vidas están tan rotas que pensar en la autonomía es un horizonte tan lejano que ni siquiera pueden tenerlo como objetivo. Tal vez en el futuro sí, pero en este momento lo que podemos hacer es trabajar para que detengan su caída, reducir daños y garantizar la supervivencia..., sin pedirles nada más.

Este planteamiento, en el fondo, nos resulta poco aceptable. Socialmente, porque supone ofrecer prestaciones a quien no está en disposición de devolver nada a cambio. Y humanamente, por la frustración que provoca ver que las personas no avanzan todo lo que nos gustaría. A pesar de ello, los años de trabajo con estas personas nos han ido convenciendo de que este trabajo es indispensable y de que les fortalece mucho más de lo que nos muestran los avances que vemos desde fuera. Hemos aprendido a valorarlo y creemos que hay que hacerlo aún más.

Por eso, en Bizitegi nos hemos animado a hacer esta reflexión. Porque pensamos que el trabajo en baja exigencia esconde mucho saber y muy buenas prácticas, que creemos que hay que mostrar. Para hacerlo, hemos contado con la colaboración directa de aquellos equipos de Bizitegi que trabajan con personas sin hogar. Y con la de muchos profesionales amigos que no han dudado en ayudarnos cuando se lo hemos pedido.

\section{Metodología}

La elaboración de este artículo la hemos estructurado en diferentes fases de trabajo:

- Una primera revisión bibliográfica, en la que constatamos la escasa presencia de documentos que profundicen sobre este tema. Tras ella, elaboramos un primer documento.

- Expusimos dicho escrito a los profesionales de Bizitegi que trabajan con las personas sin hogar, con el fin de crear un espacio en el que pudieran aportar su opinión y experiencia.
- Después, establecimos un índice de todas aquellas cuestiones que debían ir apareciendo en el artículo, con cuya estructura realizamos una serie de sesiones de trabajo en las que pudiera participar las mismas personas profesionales. En estas sesiones, creamos un primer borrador que hacía referencia al trabajo diario en los diferentes dispositivos gestionados por Bizitegi: la metodología diaria, el perfil de usuarios, la relación con la administración pública, las bases que sustentaban la existencia de este tipo de recursos y otro tipo de asuntos que ahora conforman este artículo.

- Por otro lado, elaboramos un breve documento que contenía aquellas certezas, dudas e incertidumbres sobre la baja exigencia obtenidas con la información trabajada por los grupos focales internos, y lo sometimos al contraste de una serie de profesionales externos a Bizitegi cuya aportación considerábamos importante.

- Al mismo tiempo, comenzamos a elaborar el presente artículo, el cual fuimos introduciendo todos aquellos métodos de trabajo y opiniones que iban surgiendo a lo largo de las reuniones con los profesionales externos, intentado dar forma a toda esta información en un conjunto ordenado, que es lo que creemos que es este artículo.

\section{Nuestro marco asociativo: misión, visión y valores de Bizitegi}

De manera general, Bizitegi está configurada como una entidad asociativa formada por personas socias, profesionales, usuarias y voluntarias que trabajan por la incorporación a la sociedad de las personas en riesgo o situación de exclusión social de Bizkaia, mediante procesos de intervención dirigidos a mejorar sus condiciones de vida, y a través de acciones de sensibilización y denuncia que permitan generar conciencia en la construcción de una sociedad más justa. En esta misión, consideramos la persona como el valor fundamental y la comunidad como el lugar donde ésta se desarrolla.

Todo ello es lo que configura nuestra misión como entidad, que se concreta en:

- El contacto con la realidad, mediante diagnósticos sociales y personales de situaciones de necesidad y exclusión.

- La participación activa en foros críticos de reflexión, reivindicación y propuesta sobre políticas sociales.

- Una presencia en la sociedad que colabore a que ésta se sensibilice y se abra a las personas excluidas.

- La colaboración, complementariedad y participación con instituciones públicas y privadas. Con actitud crítica ante las instituciones, enriqueciendo sus análisis con nuestro conocimiento de la realidad, y exigiendo 
e impulsando las acciones y programas necesarios.

- La promoción y el desarrollo de procesos de normalización e incorporación social.

- El acompañamiento de las realidades de las personas en exclusión, que facilita la experiencia de los valores que la persona lleva dentro, posibilita su desarrollo existencial y potencia el encuentro personal.

- Una intervención integrada y coordinada con los diferentes servicios de la red comunitaria, que aprovecha al máximo los recursos comunitarios.

- El desarrollo de respuestas creativas, integrales, globales (no sólo individuales y puntuales), normalizadas, integradas en la comunidad y adaptadas a los problemas y necesidades de las personas.

A través de nuestra visión, queremos que Bizitegi se distinga por ser:

- Sólida y participativa, con un elevado nivel de compromiso de todas las personas que forman parte del proyecto, que se manifieste en un funcionamiento caracterizado por una gobernanza participativa.

- Eficaz y sostenible, que consiga resultados objetivos y medibles, utilizando los recursos disponibles de manera responsable, con un modelo de gestión avanzada, y diversificando e innovando formas de financiación, todo ello con el fin de garantizar el cumplimiento de la misión y su impacto a largo plazo.

- Ilusionada e innovadora, que necesite de la adhesión motivada e ilusionada de todas las personas participantes para, desde ella, generar, con creatividad, formas de actuación.

- Referente de la sociedad, reconocida y con capacidad de influencia, que participe de la provisión de servicios de utilidad social, en alianza estable con las Administraciones y con las entidades con las que compartamos objetivos y valores.

- Integradora de personas voluntarias, capaz de crear espacios significativos para las aportaciones de quienes ofrecen su compromiso personal y social en la lucha contra la exclusión.

Todo ello se cimenta en nuestros valores, tales como:

- Participación: desde la afirmación de la persona y su papel protagonista, se convierte en un valor clave del proyecto. Promovemos y valoramos la participación activa de todas las personas en la marcha de la asociación y en los contextos comunitarios, desde sus diferentes papeles, con la conciencia de un proyecto común.

- Solidaridad: las personas asumen que sus capacidades alcanzan su sentido y utilidad social cuando se ponen al servicio de los intereses comunes.
- Transparencia: como garantía de honestidad en sus procesos estratégicos, de gestión y de intervención.

- Responsabilidad: cada persona debe asumir una actitud responsable en su implicación en el proyecto y, junto con las demás, en los procesos grupales y asociativos en los que participe.

Como resultado de todo esto, durante nuestros años de andadura se ha generado un modelo de acompañamiento (Asociación Bizitegi, 2010) que se constituye como principal motor de trabajo en todos los programas que vamos realizando como entidad.

\section{4. ¿En qué contexto reflexionamos sobre la baja exigencia?}

La baja exigencia no surge de la nada; los recursos no se generan en vacío. Cualquier prestación, acción o recurso existente para cubrir las necesidades sociales de las personas está sustentado en la propia sociedad como colectivo, que es quien legitima su existencia, a través de la creación de un marco normativo y legal.

\subsection{El marco social de referencia: los elementos que justifican la existencia de recursos de baja exigencia}

En este apartado, vamos a ver cuáles son los elementos, principios o valores que legitiman socialmente la existencia, el funcionamiento y el desarrollo de los recursos de baja exigencia destinados a las personas en situación de exclusión residencial grave:

- Derechos humanos: que una persona pueda acceder a un recurso que cubra una serie de necesidades que la sociedad considera básicas (alojamiento, higiene, comida, seguridad, vinculación) favorece la dignidad humana y refuerza la idea de que las personas usuarias, aunque se encuentren en alta exclusión social, son perceptoras dignas de una serie de derechos que consideramos socialmente como fundamentales.

- Supervivencia: la sociedad entiende que debe haber un recurso que satisfaga las necesidades más básicas de supervivencia, que no es humano que alguien muera en la calle.

- Seguridad: la existencia de un recurso para personas sin hogar proporciona un entorno seguro a las personas que viven y pernoctan en la calle, y evita posibles agresiones.

- Calmar conciencias: pensamos que esta idea es un tanto conflictiva. Aun así, debe aparecer, porque es una de las razones que favorece la creación y mantenimiento de estos dispositivos. Cuando las instituciones públicas, en representación de la ciudadanía, generan recursos para atender a las personas 
menos favorecidas, se reduce el sentimiento de culpabilidad que la población siente ante la existencia de dichas situaciones. Y con ello, se calma algo la necesidad que todos sentimos de ayudar a los más débiles.

- Estética: los recursos de baja exigencia generan una contención de las personas sin hogar que reduce el impacto visual que generan al estar en la calle. Esto hace que la realidad de este colectivo no sea tan visible en los diferentes barrios o municipios, lo que crea una sensación ficticia de bienestar.

- Solidaridad: toda sociedad quiere ser solidaria con el resto de personas que viven en ella, y la existencia de una serie de recursos que dignifiquen a las personas sin hogar y que provengan de entidades e instituciones sociales financiadas de manera pública, que fomentan ese sentimiento de solidaridad, ya sea por 'sentirse bien', ya sea por 'ser social'.

- Empatía: que una sociedad o territorio concreto disponga de recursos de baja exigencia viene dado, entre otras cosas, por la empatía con la situación de las personas que hacen uso de ellos, y por entender la situación en la que se encuentran y asumir que la sociedad debe dar respuesta a una serie de necesidades, generadas en algunos casos por la propia sociedad.

- Autoestima social: que una sociedad sea capaz de responder, de manera pública o privada, a través de recursos y prestaciones, a las necesidades sociales de toda la población, sea cual sea su situación, es un síntoma de fortaleza, desde la cual la sociedad puede generar servicios.

\subsection{El marco legal de referencia}

\subsubsection{Las políticas sociales europeas}

Los programas de lucha contra la pobreza a nivel comunitario reconocen la necesidad de impulsar recursos y prestaciones para combatir la exclusión social. La Recomendación 92/441/CEE del Consejo, de 24 de junio de 1992, establece la necesidad de que los países miembros dispongan recursos y prestaciones garantizadas, suficientes, estables y regulares para combatir la exclusión social, y, en este mismo sentido, tomen medidas en materia de salud, vivienda, formación y acceso al empleo.

En este marco, hay que tener en cuenta la normativa aplicable (leyes, decretos, reglamentos, planes y cualquier otro tipo de normas), la actividad de planificación de la Administración y el marco competencial. Entre la normativa internacional en materia de derechos sociales, destacamos:

- La Declaración Universal de los Derechos Humanos, de 10 diciembre de 1948:

Toda persona tiene derecho a un nivel de vida adecuado, que le asegure, así como a su familia, la salud y el bienestar; y en especial, la alimentación, el vestido, la vivienda, la asistencia médica y los servicios sociales necesarios; tiene asimismo derecho a los seguros en caso de desempleo, enfermedad, invalidez, viudez, vejez u otros casos de pérdida de sus medios de subsistencia por circunstancias independientes de su voluntad (artículo 25).

- El Pacto Internacional de Derechos Económicos, Sociales y Culturales, de 16 diciembre 1966. Es el instrumento internacional que ha desarrollado los derechos sociales y a cuyo cumplimiento se han comprometido los Estados firmantes:

Los Estados Parte en el presente Pacto reconocen el derecho de toda persona a un nivel de vida adecuado para sí y su familia, incluso alimentación, vestido y vivienda adecuados, y a una mejora continua de las condiciones de la existencia. Los Estados Parte tomarán medidas apropiadas para asegurar la efectividad de este derecho, reconociendo a este efecto la importancia esencial de la cooperación internacional fundada en el libre consentimiento (artículo 11).

- Las Observaciones Generales del Comité de Derechos Económicos, Sociales y Culturales, que complementan el pacto anterior.

- La Carta Social Europea, de 1961, del Consejo de Europa.

- En el proceso de construcción de la Unión Europea, se ha ido dando entrada a los derechos sociales en el Tratado de Maastricht, en el de Ámsterdam (1997) y en la Carta de los Derechos Fundamentales de la Unión Europea (2000). La Constitución Europea (2004) integra los derechos fundamentales en un único texto.

\subsubsection{Nuestro marco legal de referencia: la experiencia de la Comunidad Autónoma del País Vasco}

El marco principal en el que se sustenta la existencia de los recursos de baja exigencia es la Ley $12 / 2008$, de Servicios Sociales de la Comunidad Autónoma del País Vasco (CAPV) en su artículo 27.2, donde señala que los servicios sociales de atención primaria:

posibilitarán el acceso de las usuarias y usuarios al conjunto del Sistema Vasco de Servicios Sociales (SVSS) y atenderán las necesidades relacionadas con la autonomía, la inclusión social y las situaciones de urgencia o desprotección social, con particular incidencia en la prevención de las situaciones de riesgo.

Además, el artículo 3 establece una serie de principios generales de actuación por los que deben regirse los servicios sociales en la CAPV. Estos principios son generalidades que cada recurso puede concretar de acuerdo con las particularidades de su 
misión, pero nos parece interesante ver cuál es el común denominador de la red de atención:

- Responsabilidad pública.

- Universalidad.

- Igualdad y equidad.

- Proximidad.

- Prevención, integración y normalización.

- Atención personalizada e integral, y continuidad de la atención.

- Carácter interdisciplinar de las intervenciones.

- Coordinación y cooperación.

- Promoción de la iniciativa social.
- Participación ciudadana.

- Calidad.

Por su parte, el Decreto de Cartera de Servicios (185/2015) establece dos tipos de recursos destinados específicamente a la intervención en baja exigencia para atender las necesidades de las personas en exclusión residencial grave: los servicios de atención diurna para personas en situación de exclusión (ficha 1.7) y el centro de acogida nocturna para atender necesidades de inclusión social (ficha 2.3.2). Por otro lado, el servicio o centro de día para atender necesidades de inclusión social (ficha 2.2.3) admite atención en baja exigencia. Las características de estos tres tipos de servicios se recogen en los Cuadros 1, 2 y 3.

\begin{tabular}{|c|c|}
\hline Definición y objetivo & $\begin{array}{l}\text { Estos servicios ponen a disposición de las personas un dispositivo al que acudir en el día, en el que se les } \\
\text { ofrece un apoyo de baja intensidad ligado a sus necesidades específicas de atención, de modo que ofrecen } \\
\text { a las personas en exclusión un espacio donde cubrir sus necesidades básicas de alimentación e higiene, } \\
\text { entendiéndose estas situaciones como de acceso urgente. }\end{array}$ \\
\hline Prestaciones & $\begin{array}{l}\text { - Información, mediación e intermediación, intervención educativa y psicosocial (escucha activa y contención } \\
\text { emocional). } \\
\text { - Manutención en su caso, higiene personal, lavandería y consigna. }\end{array}$ \\
\hline Población destinataria & Personas en situación de exclusión social mayores de 18 años. \\
\hline Requisitos de acceso & $\begin{array}{l}\text { a. En cuanto al ámbito administrativo, no se exigirá ningún requisito al margen de la prescripción técnica, } \\
\text { teniendo la consideración de servicio de acceso directo y pudiendo acceder al servicio, por tanto, sin ser } \\
\text { necesario el paso previo por el servicio social de base. } \\
\text { b. Requerir un apoyo de baja intensidad para la cobertura de las necesidades atendidas. } \\
\text { c. No rechazar el tratamiento que corresponda, en el caso de padecer una enfermedad infecto-contagiosa y/o } \\
\text { enfermedad mental. } \\
\text { d. No padecer trastornos de conducta y/o presentar comportamiento que puedan perturbar gravemente el } \\
\text { funcionamiento del servicio o la normal convivencia en el mismo o que supongan riesgo para la propia } \\
\text { persona, para otras personas usuarias o para las y los profesionales. } \\
\text { e. No precisar de asistencia sanitaria especializada y/o permanente fuera del alcance y posibilidades de las } \\
\text { dotaciones propias del servicio. }\end{array}$ \\
\hline
\end{tabular}

Fuente: Decreto 185/2015, de 6 de octubre, de Cartera de Prestaciones y Servicios del Sistema Vasco de Servicios Sociales (pág. 33, adaptado).

\begin{tabular}{|c|c|}
\hline Definición y objetivo & $\begin{array}{l}\text { Este servicio se dirige a personas en situación de exclusión social que requieren un lugar en el que pasar la } \\
\text { noche y cubrir sus necesidades básicas, pero no pueden ser atendidas en los servicios de acogida nocturna } \\
\text { de atención primaria, debido a sus especiales necesidades o circunstancias (en particular, a situaciones en las } \\
\text { que concurren trastornos de conducta, alta hospitalaria reciente requiriéndose de apoyo en la convalecencia o } \\
\text { síndrome de abstinencia). } \\
\text { Es posible acceder con flexibilidad a intervenciones socioeducativas y psicosociales básicas que contribuyan a } \\
\text { evitar un mayor deterioro y, en lo posible, constituyan un primer paso hacia un itinerario de inclusión social. } \\
\text { Son servicios de baja exigencia y de media y alta intensidad de apoyo en la atención a las especiales } \\
\text { necesidades o circunstancias de las personas atendidas. } \\
\text { El servicio podrá prestarse en un centro de noche (integrado, o no, en un equipamiento residencial) o como un } \\
\text { servicio de atención nocturna en el marco de un servicio residencial de los previstos en la ficha } 2.4 .5 \text { y en su } \\
\text { caso, en la ficha } 2.4 .4 \text {. }\end{array}$ \\
\hline Prestaciones & $\begin{array}{l}\text { - Información, orientación y valoración de seguimiento. } \\
\text { - Intervención socioeducativa (adquisición de habilidades de higiene y pautas básicas de educación para la } \\
\text { - salud) y psicosocial (escucha y contención emocional). } \\
\text { - Pernocta, manutención, higiene personal, lavandería y ropa básica de urgencia. } \\
\text { - Servicio de intercambio de jeringuillas para personas con problemas de drogodependencia. }\end{array}$ \\
\hline Población destinataria & Personas en situación de exclusión mayores de 18 años. \\
\hline Requisitos de acceso & $\begin{array}{l}\text { a. No se exigirá ningún requisito, al margen de la prescripción técnica, accediéndose al servicio de modo } \\
\text { directo (servicio de acceso directo). } \\
\text { b. Necesitar de un lugar en el que pasar la noche. } \\
\text { c. Presentar necesidades o circunstancias que impidan o dificulten su atención en un servicio de acogida } \\
\text { nocturna de atención primaria (en particular, las tres situaciones referidas en la definición). }\end{array}$ \\
\hline
\end{tabular}




\begin{tabular}{|l|l|}
\hline \multicolumn{2}{|l|}{ Cuadro 3. Servicio o centro de día para atender necesidades de inclusión social (ficha 2.2.3) } \\
\hline Definición y objetivo & $\begin{array}{l}\text { Este servicio ofrece a las personas en situación de exclusión social asentadas en el Territorio Histórico un lugar } \\
\text { en el que pasar el día y un servicio orientado a su incorporación social, de carácter polivalente, que les presta } \\
\text { una atención prolongada en el tiempo, procurando que no se desliguen de su entorno habitual, y ofreciéndoles } \\
\text { un acompañamiento individualizado en el itinerario de incorporación, conjugando, desde un enfoque integral, } \\
\text { intervenciones de carácter ocupacional, educativas, terapéuticas y de inclusión sociolaboral. } \\
\text { Se trata de equipamientos de proximidad, flexibles y abiertos durante un amplio abanico de horas de atención } \\
\text { diurna, cuyo objetivo es dotar a la persona del máximo grado de autonomía y favorecer su inclusión social. Es } \\
\text { un servicio de media y alta intensidad de apoy. Y de baja, media o alta exigencia, requiriéndose, en todo caso, } \\
\text { a las personas usuarias el compromiso de realizar las acciones que se definan en su PAP [plan de atención } \\
\text { personalizada] y en su programación individual. }\end{array}$ \\
\hline Prestaciones & $\begin{array}{l}\text { a. Valoración de seguimiento. } \\
\text { b. Mediación-intermediación. }\end{array}$ \\
$\begin{array}{l}\text { c. Intervención socioeducativa y psicosocial: estimulativa o rehabilitadora, educativa, psicosocial, ocupacional } \\
\text { o prelaboral. }\end{array}$ \\
d. Acompañamiento social.
\end{tabular}

Fuente: Decreto 185/2015, de 6 de octubre, de Cartera de Prestaciones y Servicios del Sistema Vasco de Servicios Sociales (pág. 42, adaptado).

\section{Algunos conceptos relacionados con la baja exigencia}

Profundizar en la baja exigencia se hace difícil si antes no dibujamos un marco con algunos conceptos que, de una manera u otra, están relacionadas con ella.

\subsection{Exclusión social grave}

Este estudio se centra en los servicios dirigidos a personas en exclusión residencial grave. El fenómeno de la exclusión residencial grave vamos a abordarlo en apartados posteriores, pero antes nos parece necesario dar algunas pinceladas sobre qué es esto de la exclusión social grave, en la que, por supuesto, estaría también enmarcada la de carácter residencial.

En la CAPV, el Instrumento Técnico Común de Valoración de la Exclusión Social, anexo al Decreto $385 / 2013$, establece que las personas se encuentran en situación de exclusión social cuando sus condiciones de vida y convivencia están afectadas por múltiples carencias que persisten en el tiempo. La exclusión tiene carácter multidimensional, por lo que algunas personas o determinados grupos se ven excluidos de la participación en los intercambios, prácticas y derechos sociales que constituyen la inclusión social y, por ende, la identidad ciudadana. La exclusión social no se refiere sólo a la insuficiencia de recursos financieros, ni se limita a la mera participación en el mundo del empleo; se hace patente y se manifiesta también en los ámbitos de la vivienda, la convivencia, la educación, la salud o el acceso a los servicios. El Decreto define la gravedad en función de que se dé una precariedad o ausencia de relaciones sociales afectivas, y una escasa o nula participación en la sociedad.

En el modelo de diagnóstico social y el Instrumento de Valoración de la Exclusión Social, se establece que la exclusión social es un fenómeno de causas estructurales: las transformaciones producidas en el mercado laboral, las transformaciones en las formas de convivencia, cierta erosión del capital social que han supuesto los vínculos familiares en los países mediterráneos como barrera de protección frente al riesgo de pobreza y exclusión social, o el actual devenir del Estado del bienestar son algunas de ellas.

Como categoría diagnóstica, también está referida a la posición social que ocupa la persona en relación con los riesgos que afectan a la capacidad integradora de nuestra sociedad. En situaciones similares, las reacciones de las personas pueden ser heterogéneas en función de su capacidad de resistencia frente a los factores de exclusión, así como las estrategias personales por las cuales pueden superar las situaciones de riesgo mediante el acceso y el uso de recursos específicos.

Para analizar las situaciones de exclusión social, el Instrumento de Valoración de la Exclusión Social considera indicadores de cinco ámbitos vitales: económico-laboral-residencial, convivencial 
(alojamiento y vivienda), personal (educación y otros recursos), de la salud y social.

\subsection{Proximidad}

A nuestro juicio, la proximidad es uno de los conceptos más estrechamente ligados a la baja exigencia. En apartados posteriores, veremos cómo se establece como un principio esencial que justifica y explica la existencia de recursos de baja exigencia. Pero ¿qué es lo que legitima el principio de proximidad?

La Ley 12/2008, de Servicios Sociales, en su artículo 8 , hace referencia al enfoque comunitario y de proximidad de la atención dentro de los servicios sociales. Este enfoque favorece la adaptación de los recursos y las intervenciones a las características de cada comunidad local, posibilitando la atención de las personas en su entorno habitual, diseñando el tipo de intervención adecuada a cada caso, asignando profesionales de referencia, garantizando el carácter interdisciplinar de la intervención e incorporando el carácter preventivo en todas las intervenciones, servicios, programas y actividades. También establece que la planificación de los servicios sociales debe "posibilitar, siempre que la naturaleza del servicio y el número de personas usuarias o potencialmente beneficiarias lo permitan, la implantación de los servicios en las zonas geográficas más susceptibles de garantizar la prestación del servicio en un ámbito cercano al lugar de vida habitual” (art. 34).

\subsection{Necesidades básicas}

Vivir en la calle no es meramente carecer de una vivienda. Las personas en exclusión residencial grave tienen una serie de necesidades no satisfechas, como el alojamiento, la higiene, el alimento y el vestido, que consideramos básicas, porque afectan a la subsistencia. Su cobertura implica la creación de una serie de prestaciones de carácter asistencial, ya sea dentro de un recurso destinado específicamente a ello (comedor social o centro de pernocta) o como complemento de un servicio con otro objeto más amplio (centro de día en el que se disponga de un servicio de duchas).

Sin dejar de lado estas prestaciones y sin restarles importancia, en Bizitegi consideramos que también son necesidades básicas aquellas de carácter más psicológico, social y personal. Quizás sea imprescindible atender primero las necesidades básicas de carácter más asistencial, pues son aquellas que, en un primer momento, garantizan la supervivencia. Pero la situación de sinhogarismo genera otro tipo de necesidades cuya atención es el objeto de intervención de los recursos de baja exigencia, como la inseguridad, el desarraigo o la falta de redes sociales, familiares o personales. Dentro de las necesidades básicas, debe hacerse especial mención a aquellas derivadas de la situación administrativa, como la falta de empadronamiento o tarjeta sanitaria, que generan una gran vulnerabilidad, al impedir o dificultar el acceso a la atención sanitaria y social de las personas en sinhogarismo.

\subsection{Reducción de daños y prevención de riesgos}

Bibliográficamente hablando, la reducción de riesgos y daños ha sido un ámbito de estudio ligado a las drogodependencias. Los recursos con este objetivo tenían como misión mitigar los peligros del consumo en la vía pública, controlándolos o reduciéndolos a través de la educación en el consumo responsable, la higiene y la seguridad, entre otras cuestiones. Cuando en este estudio hablamos de reducción y prevención de riesgos y daños, nos referimos, además, a aquellos generados por la propia situación de sinhogarismo, por el desamparo de las personas en situación de calle. La adherencia, vinculación o permanencia en un recurso de pernocta, un recurso de atención diurna o en la relación con el equipo de calle mitigan ciertos efectos del sinhogarismo, como la soledad, la falta de información y de redes sociales, el riesgo de las enfermedades mentales no diagnosticadas o controladas, o la falta de ocupación del tiempo libre.

\subsection{Intensidad}

La intensidad es uno de los conceptos que va de la mano de la exigencia, tanto a la hora de intervenir como de estructurar los recursos. En ambas, se establece de manera frecuente una estructura de niveles (medio, alto y bajo), que determina la intervención que se realiza con las personas usuarias.

La intensidad aplicada a la intervención en los servicios sociales, y concretamente en los recursos de los que estamos hablando, hace referencia al nivel de apoyo profesional; tanto en número de profesionales como en acompañamiento. Ésta puede determinar el tipo de recurso - es decir, todas las personas usuarias de un servicio reciben la misma intensidad de apoyo-, o puede establecerse de manera individualizada, de acuerdo con la necesidad de atención de cada una.

\subsection{Salud mental}

Según el II Estudio sobre la situación de las personas en situación de exclusión residencial grave en la CAPV (SIIS Centro de Documentación y Estudios, 2015: 130), el 15,2\% de las personas en exclusión residencial grave encuestadas tienen una enfermedad mental (lo que supone el 37,3\% del total de personas con alguna dolencia grave o crónica). Por otro lado, la concurrencia del sinhogarismo y de algún tipo de enfermedad mental aumenta la exclusión social. Muchas de estas personas tienen 
grandes dificultades para vincularse con los servicios de salud mental normalizados. Esto, añadido a la cronicidad y el deterioro social, redunda en un incremento de las dificultades de inserción, de modo que se detecta un subgrupo de personas que se quedan al margen de cualquier servicio de salud y, por tanto, privadas, como hemos apuntado anteriormente, de un tratamiento psiquiátrico rehabilitador adecuado (Garay et al., 2012).

Todo ello hace que hayan surgido recursos que, desde la baja exigencia, traten de aproximarse a este colectivo de la manera más efectiva posible, como por ejemplo, el Programa de Asistencia Psiquiátrica a Personas Sin Hogar con Enfermedad Mental Grave en el municipio de Bilbao (cfr. ídem).

\section{La mirada desde la baja exigencia}

En este estudio, no pretendemos dar verdades absolutas ni categorizar en extremo los recursos que hoy día existen y dan cobertura a la población en situación de exclusión residencial. Nuestro objetivo es decir algunas cosas con sentido en relación con los dispositivos que gestionamos, al perfil de personas que atendemos y a la intervención que realizamos los profesionales de la red de atención social. Para ello, hemos contado con la colaboración de profesionales externos a Bizitegi que nos han aportado su visión de aquellas cuestiones que afectan, definen y estructuran el modelo de trabajo en baja exigencia desde el mayor número de perspectivas posibles.

\subsection{Las incógnitas previas y puntos de partida}

La idea principal de la que partimos en Bizitegi es que la baja exigencia hace referencia a tres perspectivas: la persona, los recursos y la intervención. En esta idea también profundiza Txema Duque (Ayuntamiento de Bilbao), comentando que una cosa es la visión de lo que nosotros exigimos (profesionales, instituciones y Administraciones), por lo que se crean dispositivos con unos perfiles de exigencia bajos, y otra, lo que la persona se exige a sí misma en su proceso personal, que es lo que acaba determinando la intervención.

También Joseba Gaya (Cáritas Bizkaia) señala que la baja exigencia tiene una doble vertiente: una que marca qué debo pedir a las personas usuarias, y otra que define el servicio en sí y el tipo de personas que van a llegar a él. Para Joseba, la evolución de los últimos quince o veinte años muestra que cada vez necesitamos una mayor flexibilidad y adaptación a la persona. Si marcamos un determinado perfil que limite el acceso a los recursos, podemos provocar que disminuyan las oportunidades de personas que no encajan en dicho perfil.

En opinión de Txema Duque, no sabemos si la baja exigencia en relación a la intervención es una metodología per se, o es más bien una manera de entender el trabajo diario que realizamos en las entidades y recursos, se denominen 'de baja exigencia’ o no. Además, según Txema Duque, Ander Zugaza (Etorkintza) y José Bosque (Etorkintza), nos enfrentamos a la idea socialmente preponderante de que el acceso a la protección social debe implicar algún tipo de contraprestación por parte de la persona que la recibe. Esto es contradictorio con el concepto de baja exigencia, según el cual, tenemos derecho a recibir una atención sólo por el hecho de ser personas, sin que ello implique hacer nada a cambio.

Hoy día existen recursos que, en su definición, llevan explícito algún tipo de exigencia. ¿Debe ser esto así?, ¿ha de haber recursos de alta, media y baja exigencia? Desde el punto de vista de la gestión, sabemos que es más fácil estructurar de esta manera los dispositivos, pues generan unas normas para todas las personas usuarias que favorecen el trabajo tanto para ellas mismas como para los equipos educativos y profesionales que las atienden. Con todo, en Bizitegi coincidimos con Txema Duque al creer que lo ideal sería que los recursos se definieran por sus objetivos y las prestaciones que ofrecen, y que las exigencias fueran personalizadas, según los momentos y necesidades de las personas usuarias. En esta idea incide Mariasun Garay (Red de Salud Mental de Bizkaia) cuando indica que la misma toma de contacto con un dispositivo puede resultar de una mayor exigencia para unas personas que para otras. Y esto nos lleva a la necesidad de individualizar el tratamiento, sin pretender ofrecer 'café para todos'.

\subsection{Las personas en situación de exclusión residencial grave, usuarias potenciales de los recursos de baja exigencia}

En este apartado, y aprovechando la reciente publicación del II Estudio sobre las personas en situación de exclusión residencial grave en la CAPV (SIIS Centro de Documentación y Estudios, 2015), vamos a ver algunos datos relativos a la población que se encuentra en situación de sinhogarismo y pernocta en la calle o utiliza los dispositivos de atención a personas sin hogar.

\subsubsection{Situación actual de las personas en exclusión residencial grave}

La conceptualización del sinhogarismo en el citado estudio tiene como referente teórico el trabajo desarrollado por la Federación Europea de Organizaciones Nacionales que trabajan con Personas sin Hogar (Feantsa) en el marco del Observatorio Europeo sobre las Personas sin Hogar. Así, distingue tres dimensiones en el concepto de hogar:

- Física: condiciones de habitabilidad (instalaciones e infraestructura). 
- Legal: nivel de seguridad jurídica; derechos vinculados a la propiedad o al usufructo de ésta (título de propiedad o alquiler).

- Social: calidad de las relaciones que se establecen entre las personas que forman parte de una misma unidad convivencial.

La existencia de carencias en alguna de estas dimensiones da lugar a distintas formas de sinhogarismo y exclusión residencial. Partiendo de esta base y de la consideración de la Tipología Europea de Sinhogarismo y Exclusión Residencial (ETHOS), el estudio analiza los datos recogidos en el recuento de personas localizadas en calle y en centros y servicios de alojamiento en la CAPV durante la noche del 29 al 30 de octubre de 2014. Los resultados principales son los siguientes:

- Casi dos mil personas en la CAPV están en sinhogarismo. En Bizkaia, se concentran 904: 175 pernoctan en calle, y 729 , en recursos de alojamiento. En Bilbao, la cifra es de 736 personas, de las cuales 141 se encuentran en situación de calle, y 595, en recursos de alojamiento.

- En relación con las características sociodemográficas básicas:

- Ocho de cada diez personas sin hogar son hombres.

- La edad media es de 37,1 años.

- Las personas menores de 25 y las mayores de 55 son quienes acceden en mayor medida a recursos con alojamiento de media y larga estancia.

- El 41,5\% son de nacionalidad española.

- En cuanto a la caracterización ${ }^{1}$ :

- El 90\% están empadronadas, aunque el $45,95 \%$ de las personas extranjeras no tienen permiso de residencia, lo que deriva en una situación administrativa irregular.

- El $60 \%$ no tiene estudios o sólo cuenta con estudios primarios.

- Sólo el $6 \%$ trabaja de forma estable y un $17 \%$ realiza actividades informales.

- El $21 \%$ de las personas encuestadas carecen de ingresos propios, frente al $16 \%$ que los obtienen por actividades laborales y semilaborales. Algo más de 4 de cada 10 personas tienen como principal fuente de ingresos las prestaciones económicas públicas, siendo el $18 \%$ prestaciones correspondientes a la renta de garantía de ingresos (RGI). Un tercio de las personas entrevistadas llevan un año sin hogar, y otro tercio, más de tres años.

- El $60 \%$ de las personas que han pernoctado en la calle alguna vez han sido víctimas de algún delito, sobre todo, mujeres.

${ }^{1}$ Tal y como se indica el estudio, estos porcentajes hacen referencia a las personas que respondieron al cuestionario, que son el $67 \%$ de la población contabilizada durante la noche del recuento.
- Más del $25 \%$ de las personas en situación de exclusión residencial grave pasan la mayor parte del día solas.

- El $11 \%$ de los entrevistados consideran que tienen un estado de salud malo o muy malo, y el $40 \%$ declaran sufrir una enfermedad grave o muy grave.

- Las personas sin hogar consumen tabaco y cannabis en mayor medida que el resto de la población ( $55 \%$ frente al $25 \%$ ), aunque no sucede lo mismo con relación al consumo de alcohol, puesto que el $56 \%$ de las personas encuestadas no han consumido alcohol en el último año, frente a apenas el $26 \%$ del conjunto de la población.

\subsubsection{La problemática del perfil atendido y la razón por la que existen los recursos de baja exigencia}

Debemos hacernos la pregunta: ¿todas las personas que se encuentran en esta situación necesitan una intervención desde la baja exigencia? Partimos de la premisa de que hay personas que acceden a servicios de alojamiento nocturno o centros de día de baja exigencia y que no precisan de una intervención de esas características. En referencia a esto, Amaia Porres, de Lagun Artean, nos comenta que la situación de las personas que atienden en sus propios recursos de alojamiento y cobertura diurna responde a un perfil mayoritario de jóvenes inmigrantes en alta exclusión social, cuya autonomía personal, relacional y cognitiva es alta, pero con carencias básicas que las prestaciones ofertadas en los recursos configurados desde la baja exigencia se encargan de cubrir.

Las personas con las que trabajamos en los dispositivos que gestiona Bizitegi presentan, en muchos casos, situaciones de desarraigo y desamparo, asociadas normalmente a un largo proceso de sinhogarismo. Esto exige un proceso de intervención más amplio que la satisfacción de necesidades de vestido, alojamiento, higiene 0 comida. Son, tal y como nos comentan Ander Zugaza y José Bosque, una población que, sin la existencia de estos recursos, no podría sentar las bases para avanzar en su recuperación.

En algunos casos, las prestaciones básicas ofrecidas en contextos de baja exigencia son la mejor garantía de supervivencia con las que cuentan estas personas. Sin ellas, su vida podría estar en peligro.

\subsubsection{El papel de la persona usuaria en su propio proceso de intervención}

El grueso de personas que son atendidas por los recursos de baja exigencia, o que son susceptibles de iniciar un proceso desde la óptica de la baja exigencia, están en una fase avanzada de desarraigo social, personal, laboral y familiar (Ararteko, 2006). Presentan numerosas carencias sociales 
y personales que provocan que no sean capaces de adecuarse a los ritmos de trabajo y normativas de los dispositivos de la red social y sanitaria con una exigencia media o alta. En algunas ocasiones, además, sufren trastornos de carácter psicológico o de drogodependencias y, en general, tienen de algún modo comprometida su salud. En cuanto al ámbito económico, la mayoría no posee recursos suficientes para llevar una vida estable y desarrolla básicamente una economía de subsistencia. Con todo esto, podemos decir que su estabilidad y, en muchas ocasiones, su supervivencia dependen de la existencia de una serie de recursos que se adapten a su situación y capacidades.

En la mayoría de los casos en los que las personas acceden a un recurso de baja exigencia, lo hacen de manera voluntaria, por lo que en Bizitegi entendemos que deben asumir cierto grado de responsabilidad. Esto quiere decir que los profesionales han de dotarlas de la mayor cantidad de recursos disponibles para facilitar una mejora de su situación, pero está en la propia persona asumir y comprender que, para el desarrollo de un buen proceso de intervención, es necesaria su implicación. Esta responsabilidad no podrá surgir si la persona no tiene decisión sobre su propio proceso. El usuario es sobre el que recaen los efectos de la intervención, por lo que debe ser responsable de aquellas decisiones que toma.

Como resultado de esta responsabilidad, las personas deberán trabajar la aceptación de aquellas limitaciones propias y de los recursos que van a determinar el ritmo del proceso, y los objetivos y las metas que van a conseguir con la intervención. Esto es algo que los y las profesionales deben manejar con tino. Una visión irreal de las capacidades de las personales atendidas puede generar un nivel de frustración suficiente como para que la intervención no llegue a buen término.

El deseo de cambio es el mejor motivador de cualquier intervención. Por ello, desde esta perspectiva, los y las profesionales, las entidades y las Administraciones deben poner una serie de recursos e intervenciones al alcance de la persona usuaria, para ayudarla a descubrir cuáles son sus posibilidades de cambio, hacia dónde puede orientar sus deseos.

\subsection{Los principios que rigen la configuración de los dispositivos de baja exigencia}

Queremos dar una visión global de aquellos principios que determinan por qué, para qué y cómo funcionan los recursos de baja exigencia, a través del análisis de aquellas cuestiones que marcan su ubicación, idoneidad y permanencia en un entorno o medio concreto, así como de las que marcan la entrada de las personas usuarias.

\subsubsection{Principios que determinan el acceso a los recursos de baja exigencia}

Los dispositivos de baja exigencia, como primera línea de la red de prestaciones sociales, no pueden determinar el acceso de una manera cerrada. Este tipo de recursos han de estar adaptados al funcionamiento, las especiales circunstancias de sus usuarios, y a los posibles cambios sociales que vayan surgiendo, posibilitando, entre otras cosas, la entrada del mayor volumen de población posible. Esta adaptación pasa por ser próximos a las personas, configurándose así como una oportunidad para motivar y, siempre que sea posible, iniciar procesos de mejora en la situación de las personas usuarias, permitiendo que éstas puedan utilizar recursos de la red normalizada de atención social. En este sentido, la baja exigencia no ha suponer, en ningún caso, renunciar a conseguir progresos en la incorporación de estas personas a centros o servicios que permitan superar su situación, pero deben dar servicio a cualquier persona, decida o no empezar un itinerario de inserción.

La baja exigencia debe ofrecer la cobertura de las necesidades básicas de alojamiento, alimentación, vestido, higiene, acompañamiento o vinculación, sin otra condición que la de no suponer una amenaza o riesgo para las propias personas beneficiarias, otros usuarios, los profesionales o el entorno en el que se mueven. Por ello, el modo de acceso debe ser inmediato, es decir, la persona no puede verse inmersa en una sucesión de trámites burocráticos y requisitos administrativos que dificulten el acceso, sino que los pasos que ha de seguir deben ser ágiles, sencillos y bien gestionados dentro de las entidades tanto públicas como privadas. Esta inmediatez, además, está sustentaba, tal y como nos comenta Álvaro Ortiz de Zarate, coordinador de la Asociación T4 de Lucha contra el Sida, en el carácter de urgencia que tienen los recursos, responsables de ofertar una serie de prestaciones que garantizan la supervivencia de las personas en situación de exclusión residencial grave.

Todo lo anterior, unido a las características de las personas usuarias, hace que los centros de baja exigencia tengan que diseñar el acceso, los requisitos y la normativa de forma que permitan una aplicación flexible. Las personas responsables de estos centros han de establecer, asimismo, protocolos internos para que la flexibilidad se aplique con criterios técnicos en cada intervención y para evitar la discrecionalidad.

Amaia Porres piensa que, en ocasiones, los profesionales debemos saltarnos algunas normas establecidas, pues nuestro criterio profesional educativo siempre tiene que estar por encima de ellas, bien porque consideramos que es lo correcto para el buen desarrollo de nuestra intervención, bien para garantizar la permanencia de la persona usuaria en el recurso. 
Para Bizitegi, el acceso y la permanencia en estos dispositivos deben cumplir los principios de inmediatez, flexibilidad, adaptación y proximidad comentados anteriormente, ya que una incorrecta estructuración puede provocar, entre otras cosas, que estas personas vayan a la calle y abandonen el circuito de los servicios sociales y la atención primaria.

Ser laxos y tolerantes en cuanto al acceso y permanencia de las personas usuarias en los recursos no debe implicar la ausencia de normas, porque éstas, aparte de favorecer el funcionamiento de los dispositivos, sirven de herramienta de trabajo en numerosos ámbitos:

- Crean un sistema de contención para las personas que se encuentran en una situación desestructurada.

- Su aplicación en un sentido educativo, y no desde el miedo, transmite a los usuarios y usuarias respeto por parte los profesionales, ya que éstos se preocupan por las acciones y las consecuencias de sus actos.

- Cuando las normas son pocas, pero concretas y bien diseñadas, estructuran tanto a las personas como la labor de los profesionales y los objetivos de su itinerario de intervención.

- Contribuyen a crear una dinámica grupal que favorece el trabajo de los profesionales y previene, en la medida de lo posible, agresiones o situaciones graves futuras si se aplican de manera efectiva.

Los profesionales deben aplicar las normas desde una autoridad previamente ganada, y no al revés. Lo primero que tienen que hacer es resultar significativos para las personas que atienden: ganar autoridad porque les sirven de algo, porque son de utilidad para ellos, porque son referencia.

Complementando estas ideas, Mariasun Garay nos comenta que cualquier exigencia debe estar supeditada a una serie de normas de convivencia. Cabe plantearse dónde están los límites de la norma, si deberían ser únicamente los marcados por la legalidad. Como ejemplo, nos cita el hecho de que, en ocasiones, se obliga a las personas a que se duchen para acceder a determinado recurso, pero lo cierto es que ir sin ducharse no es susceptible de delito ni incumple ninguna ley; habría que pensar si este tipo de normas han de mantenerse.

En esta delimitación que hacíamos anteriormente de que las normas han de ser pocas, se crea un embudo demasiado amplio, y habría que estructurarlas de modo más revisado y conciso. Por ello, Mariasun nos comenta que, en vez de profundizar en las normas, sería importante dar protagonismo a la cultura organizacional, a cuál es el clima (cultura de movimiento, de identificación, de referencia, de desarrollo, de avance) que queremos tener en un recurso de baja exigencia. Desde su experiencia, cree que no hay que hacer clima de la norma, práctica frecuente en ocasiones. El peligro de hacerlo es que, al final, la aplicación de las normas acaba convirtiéndose en una dictadura. Complementariamente, a veces las rutinas se convierten en normalizaciones, lo que conlleva estandarizar protocolos, porque se llevan haciendo así toda la vida, y quizás, llegados a este punto, se hace necesario pararse y tomar perspectiva.

A este respecto, Rakel Santurde, del Servicio Municipal de Urgencias Sociales de Bilbao, nos comenta que, para las trabajadoras de este servicio, el objetivo fundamental del apoyo educativo en los recursos de baja exigencia ha de ser generar un ambiente, no tanto dar prestaciones a necesidades de personas concretas. Esto no quiere decir que no se atienda a las individualidades, a las demandas de las personas, pero este ambiente ha de ser en lo que se base, en primera instancia, el apoyo educativo.

\subsubsection{Principios que determinan la ubicación de los recursos de baja exigencia}

La decisión de localizar en un punto concreto cualquier centro de atención a personas en situación de exclusión residencial grave en el territorio ha de llevarse a cabo analizando con detalle su impacto en el entorno más inmediato, y en su caso, estableciendo las medidas necesarias para reducir las consecuencias negativas que pudieran generar en el vecindario. Los centros de baja exigencia atienden, de manera general, a personas que se encuentran viviendo o pernoctando en el mismo territorio, por lo que su ubicación debe establecerse allí donde está la comunidad vecinal más cercana, con la meta de favorecer el arraigo.

Para Amaia Porres, esta reflexión tiene sus matices, pues en la actualidad tenemos en calle un colectivo mayoritario de inmigrantes sin un arraigo en un barrio concreto, por lo que, para este perfil, ésta no es una variable que se ha de considerar para determinar la ubicación de un recurso de baja exigencia. Además, desde su perspectiva, las personas que se encuentran en la calle en contextos urbanos no pernoctan en aquellos puntos en los que se desarrolló su arraigo, sino que huyen de ellos por razones de vergüenza y estigmatización.

Profesionales como Amaia Porres, Mariasun Garay o Rakel Santurde opinan que, para la planificación, es importante tener en cuenta un hecho que está ocurriendo en la actualidad en Bilbao. Por el volumen de población y extensión de la ciudad, los recursos se encuentran disgregados por todo el municipio. Esto hace que las personas usuarias deban desplazarse, a menudo, distancias demasiado largas para el estado de deterioro físico en que se encuentran. Este hecho supone una dificultad añadida a la exclusión residencial grave e implica, además, una dificultad para los profesionales a la hora de estructurar prestaciones e intervenciones. Esto está provocando que, en ocasiones, los centros de baja exigencia 
se conviertan en centros de alta exigencia para las personas usuarias, que deben cumplir la estructura horaria de los diferentes dispositivos. Ello se traduce, para Mariasun Garay, en una grave dificultad para planificar las consultas y las intervenciones en salud mental con las personas en situación de calle cuando tienen horarios fijos para comer, dormir o vestirse, y origina una saturación de los servicios a horas puntuales del día.

\subsubsection{Principios en los que se basa la relación con el entorno}

Uno de los principios esenciales que determinan el modo en el que los dispositivos de baja exigencia se relacionan con el entorno es el conocimiento y diagnóstico de la realidad, relacionado con la satisfacción de las necesidades del entorno. En Bizitegi, consideramos que lo ideal para la apertura de uno de estos servicios sería realizar una comunicación previa de su existencia a todos los agentes comunitarios, aunque por experiencia sabemos que esto no garantiza su aceptación. Otro punto importante es la firmeza. Las decisiones que se toman (existencia de un dispositivo, localización, perfil al que atiende) deben estar basadas en un planteamiento bien estructurado, acompañado de un aval por parte del resto de las instituciones, servicios y entidades que legitime el recurso.

La relación que las entidades mantienen con el espacio en el que conviven no debe ser instrumental. Al entrar en un barrio, adquirimos una responsabilidad con él. Esto hace que debamos incluir los recursos de baja exigencia en las redes formales e informales, a través de la participación e implicación en sus dificultades y dinámicas comunitarias. Si pretendemos que el entorno nos incluya, debemos incluirnos en él. Para lograrlo, debemos hacer un ejercicio de conocimiento de aquellas intervenciones que otros grupos o entidades realizan tanto en la zona en la que nos encontramos como para con los usuarios que atendemos.

Para todo ello, hay dos valores que resultan fundamentales: la sinceridad y la honestidad. Este punto es quizás uno en los que más hincapié debemos hacer, pues pensamos que, durante mucho tiempo, ha sido un lastre a la hora de relacionarnos con la comunidad en la que nos encontramos. Los profesionales que trabajamos desde la baja exigencia debemos cambiar nuestro discurso. No trabajamos sólo por la inclusión social, trabajamos por la normalización. Con esta idea, queremos transmitir que entendemos que hay personas que quizás no vayan a tener una inclusión como hasta ahora hemos entendido: no van a tener el funcionamiento que socialmente se puede considerar como normal, sino que está en nuestra responsabilidad, y en la de la sociedad en general, aceptar las limitaciones que tienen y contemplar la idea de que 'harán lo que esté a su alcance'. Esto no significa resignarse a que no tengan un itinerario de inclusión, sino que éste se adaptará a las necesidades y a la situación en la que se encuentren. La asunción de este principio será esencial en la defensa de la existencia de los recursos de baja exigencia, pues las expectativas que nosotros mismos generamos en la sociedad serán más fácilmente cumplidas y evitaremos que cunda la sensación -y, en ocasiones, la certeza- de que no llegamos a los parámetros que nosotros mismos habíamos establecido.

\subsection{Los recursos de baja exigencia}

Para clasificar los dispositivos denominados 'de baja exigencia’, la Administración los ha diferenciado según las necesidades que satisfacen:

- Cobertura nocturna:

- Café y calor.

- Centros de acogida nocturna (pernocta).

- Cobertura diurna:

- Comedores.

- Centros día de baja exigencia.

- Servicios en medio abierto:

- Equipos educativos de calle.

- Equipos de atención psiquiátrica en calle.

A menudo, los recursos se identifican con la cobertura de una determinada necesidad, pero en ocasiones pueden existir recursos donde las coberturas se solapen o donde se den diferentes prestaciones. En cuanto a los servicios que ofrece cada recurso, nos gustaría puntualizar que no tienen por qué estar presentes en todos los dispositivos, sino que, en función de su configuración y estructura, cada cual podrá ofrecer unos u otros.

\subsubsection{Recursos de baja exigencia de cobertura nocturna}

Los recursos de baja exigencia de cobertura nocturna son de carácter colectivo, diseñados para cubrir principalmente necesidades de alojamiento de las personas en situación de exclusión residencial grave. Históricamente, se han caracterizado por la temporalidad baja o media, y por el trabajo en contención y reducción de daños. Nos parece necesario hacer hincapié en el término 'históricamente', porque en la actualidad existen numerosos casos en los que las personas usuarias de estos recursos pasan años en ellos, ya sea por las carencias que presentan dichas personas o por la falta de otros dispositivos de temporalidad más larga que se adecuen a sus capacidades.

En cuanto a las prestaciones, de manera general se concretan en las siguientes:

1. Satisfacción de necesidades básicas:

a. Cama y habitación.

b. Alimento.

c. Higiene personal y ropa. 
d. Taquillas.

e. Café y calor.

f. Ropero.

2. Intervención psicosocial:

a. Acompañamiento social.

b. Educación para la salud.

3. Administración de medicación.

4. Asesoramiento y gestión.

5. Administración económica:

a. Gestiones y documentación.

b. Orientación legal y laboral.

6. Coordinación con otros recursos de atención social y sanitaria, tanto públicos como privados.

\subsubsection{Recursos de baja exigencia de cobertura diurna}

Los recursos de baja exigencia de cobertura diurna pueden ser complementarios, o no, de los de atención nocturna. Su misión principal es satisfacer las necesidades básicas (alimento, higiene y vestido) de las personas en exclusión residencial grave, y el aporte de un espacio seguro. Este espacio no suele estar supeditado al inicio de procesos de cambio, sino que se configura como un lugar en donde estar y encontrar cierta contención y seguridad, sobre todo para quienes, por su deterioro físico o psicosocial, o por el momento vital en que se encuentran, no pueden iniciar un camino de incorporación social. En definitiva, se configuran como una opción para aquellas personas que se quedan fuera de la red de atención social, por no poder adecuarse a las normativas y ritmos del resto de dispositivos existentes.

En cuanto a las prestaciones, atienden, al igual que los de cobertura nocturna, a multitud de necesidades:

1. Satisfacción de necesidades básicas:

a. Espacio café-calor.

b. Ducha y lavadora.

c. Cuidado de la imagen personal.

d. Taquillas.

e. Ocupación del tiempo libre (ordenador, actividades lúdicas).

2. Intervención psicosocial:

a. Acompañamiento social.

b. Soporte emocional.

c. Encuentros individuales y grupales para el soporte emocional y el trabajo en los procesos personales.

d. Encuentros de trabajo en habilidades básicas (convivencia, respeto, relaciones sociales, pertenencia, seguridad).

3. Asesoramiento y acompañamiento:

a. Jurídico.

b. Formativo-laboral.

4. Participación social, sensibilización y denuncia.
5. Atención sociosanitaria:

f. Acompañamiento sociosanitario.

g. Hábitos de vida saludables, y reducción de riesgos y daños.

h. Programas de intercambio de jeringuillas ${ }^{2}$.

\subsubsection{Servicios de baja exigencia en medio abierto}

Los servicios de baja exigencia en medio abierto atienden en primera instancia las necesidades más básicas. Normalmente, su intervención está orientada a la toma de contacto con las personas sin hogar que no acceden a la red de recursos para la atención social, bien sea porque no pueden, bien porque no quieren. Este tipo de dispositivos se orientan, además, a la reducción de daños y prevención de riesgos generados tanto por la situación en la que viven como por los posibles hábitos perjudiciales que tienen. También garantizan una relación con el sistema de protección social, con independencia de que estas personas accedan a un recurso de 'medio cerrado'.

En cuanto a las prestaciones, nos parece interesante la función pública y comunitaria que tienen los equipos de calle como complemento de las intervenciones de los servicios sociales y sanitarios, así como la labor de identificación de las personas sin hogar a través de los recuentos realizados:

1. Acompañamiento a diversos recursos.

2. Detección de casos desatendidos tanto por los recursos sociales como por los de salud mental normalizados.

3. Documentación y gestiones:
a. Proceso de empadronamiento social.
b. Información y apoyo en trámites (DNI, pasaporte, tarjeta sanitaria).
c. Gestión económica.

4. Elemento coordinador con los recursos y entidades del entorno.

\subsubsection{La baja exigencia en el ámbito residencial de alta intensidad}

Los recursos descritos hasta ahora en este apartado son los que históricamente se han denominado 'de baja exigencia'. Pero nos parece relevante comentar que, hoy día, existe otro tipo de centros, en este caso de atención secundaria (competencia foral en la (APV), que, configurados como de alta intensidad de apoyo, trabajan desde la óptica de la baja exigencia. Entidades como Zubietxe o T4, entre otras, cuentan con dispositivos organizados según un modelo de

${ }^{2}$ Este tipo de programas no son propios de todos los recursos de cobertura diurna a los que estamos haciendo referencia en el artículo, pero consideramos que juegan un papel importante en la mejora de la calidad de vida de las personas susceptibles de ser atendidas en ellos. 
reducción de daños y baja exigencia en atención secundaria, interpretando que esto garantiza procesos largos de estancia en las unidades residenciales de este sector de la atención.

Para algunos profesionales, la baja exigencia entendida como adscrita a recursos de atención primaria establece que ésta sólo puede darse en una etapa primaria de la intervención social. Pero según nos manifiesta Jon Garmendia, de Zubietxe, también puede ofrecerse en una etapa finalista, y por ello, en la atención secundaria.

\subsection{La intervención en baja exigencia}

Queremos remarcar la idea de que cuando una persona accede a uno de estos servicios, no está obligada a iniciar un proceso de inclusión. Vamos a ver que la intervención en baja exigencia está determinada por la capacidad de la persona de decidir sobre su propio proceso, y el respeto de los profesionales a sus momentos, tiempos y capacidades.

Para nosotros, la intervención en baja exigencia es una perspectiva de trabajo mediante la cual, a través de una serie de características y métodos que veremos en este apartado, se establece un diálogo y un proceso con la persona usuaria dentro de un recurso configurado para la atención de las necesidades de quienes están en situación de exclusión residencial grave, al margen de que el recurso se denomine 'de baja exigencia', o no. Esta idea está en sintonía con la opinión de profesionales como Álvaro Ortiz de Zarate, que nos comenta que la intervención en baja exigencia es una actitud ante la relación con el usuario y usuaria, ligada a la reducción del riesgo y el daño, con una gran tolerancia desde el punto de vista profesional.

\subsubsection{Finalidad de la intervención}

Creemos que estos dispositivos y sus intervenciones se configuran para dar asistencia a través de la atención a las necesidades básicas del colectivo de personas en exclusión residencial grave. Por ello, en un primer lugar la intervención social pasa por la garantía de la supervivencia, mediante la satisfacción y mejora tanto de las necesidades físicas y sanitarias (alojamiento, comida, descanso) como de las psicológicas y sociales. Esta asistencia se convierte en prioritaria en muchas ocasiones (esto se ve más claramente en los recursos de cobertura nocturna), pues no cabe un proceso de intervención si la persona no tiene satisfechas las necesidades básicas relativas a la supervivencia

En Bizitegi, entendemos que es fundamental intervenir respetando la dignidad de cada persona. Debemos analizar nuestras intervenciones desde esta perspectiva, de modo que nos aseguremos de que todas y cada una de ellas lo hacen.
De especial importancia es la prevención de los riesgos derivados de la situación en la que se encuentran quienes están en alta exclusión social (falta de hogar, consumo de sustancias, carencias psicosociales, trastornos psicológicos), así como la reducción de daños de aquellas prácticas que se consideran nocivas para la salud física, mental y social.

Otra de las finalidades que tienen los recursos de intervención en baja exigencia es la normalización del colectivo de personas sin hogar. En Bizitegi, creemos que ésta pasa por que la sociedad acepte la diversidad. No buscamos que todo el mundo se sume a la norma, sino que la generalidad, el conjunto, entienda que existe diversidad y que acepte la dignidad de las personas a las que atendemos. Por ello, nuestro mensaje debe ser claro, sin intentar esconder ni la intervención que hacemos, ni las personas que la reciben.

Otro objetivo de los recursos de baja exigencia debe ser promover que la intervención que realizamos genere la mayor estabilización y mejora posible, con el fin de facilitar el acceso a los mismos recursos, prestaciones, derechos y obligaciones que disfruta el resto de la sociedad; y ello, sin perder nunca de vista el hecho de que siempre habrá personas que tendrán limitaciones, carencias y dificultades añadidas.

\subsubsection{Los principios que rigen el trabajo en baja exigencia}

Esta metodología de trabajo ha de respetar algunos principios que deben estar en el espíritu de todo lo que hacemos, formando parte de la cultura de las personas profesionales, y de los dispositivos de atención.

El primero lo podríamos denominar principio de no contraprestación. Significa no pedir a la persona nada a cambio de los servicios que le estamos ofreciendo. Estas prestaciones tienen su origen en el reconocimiento de la dignidad de la persona y en el derecho que tiene, por ello, a recibir atenciones. Es algo que recibe por 'ser', no por 'hacer'. Como dice Txema Duque, aunque no exijamos a la persona conseguir metas a cambio de nuestra atención, está claro que alguien que se encuentra en mejores condiciones (gracias, en parte, a nuestro apoyo) tendrá mayores probabilidades de esforzarse para progresar. En otros ámbitos, recuerda Txema, como el de la discapacidad, el discurso social predominante es el de los derechos. Esto no pasa en el mundo de la exclusión, en donde hay una opinión generalizada de que las personas llegan adonde están por culpa de errores pasados propios.

Un segundo principio es el de la no sobreprotección. $\mathrm{Si}$ tendemos a actuar protegiendo a las personas que atendemos, lo que estamos haciendo, en el fondo, es instarles a que asuman el contra rol del débil, del necesitado, de alguien incapaz. Según 
Txema Duque, ésta podría ser la cara negativa del discurso de los derechos. Desde un punto de vista terapéutico y de intervención social, tiene sentido pedir a las personas que se responsabilicen de su vida lo máximo posible, sin pedir demasiado, pero tampoco demasiado poco. Distinguir entre estas dos situaciones es lo que hace difícil la labor de los profesionales.

Por ello es por lo que consideramos que el trabajo en baja exigencia es de alta exigencia para los profesionales. Manejar bien estas dinámicas de relación con las personas usuarias, no exigiendo contraprestación, motivándolas para que den aquello que está a su alcance, no culpabilizando, no permitiendo el inmovilismo ni la desesperanza, por ejemplo, es una labor para personas trabajadoras altamente capacitadas. Así, tres de las cualidades más importantes de quienes trabajan en esto son la flexibilidad, la creatividad y la firmeza. Y saber combinarlas en función de lo que cada situación requiere es la verdadera capacitación que deben tener los buenos profesionales de esto.

Un último principio podríamos denominarlo como el principio de la exigencia variable. Como dice Txema Duque, hablar de baja exigencia requiere muchos matices. En realidad, la baja exigencia está más marcada por unos principios de intervención que por una metodología. Podríamos definirla como el mayor grado de adaptabilidad a la persona que podemos tener dentro de un contexto (el de los servicios sociales, cada dispositivo, el contexto social, las personalidades de quienes intervienen) que tiene sus limitaciones.

La clave es la adaptabilidad referida tanto a las necesidades como a los momentos, los tiempos y a las decisiones de la persona. Esto quiere decir que, sean cuales sean los objetivos que los profesionales nos marquemos con las personas usuarias, debemos ser flexibles y estar abiertos a modificarlos en función de la situación en la que se encuentre, por lo que, en muchas ocasiones, el proceso no será lineal. Esto acarrea que los objetivos que nos marcamos con la persona usuaria que quiere iniciar un proceso en un recurso de baja exigencia sean personalizados, y esta personalización pasa básicamente por respetar los momentos, decisiones y tiempos de cada persona.

\subsubsection{Las herramientas de la intervención en baja exigencia}

La principal herramienta que tenemos los profesionales para intervenir desde la baja exigencia es el acompañamiento social a través del trabajo desde el vínculo. Ninguno de estos dos elementos es específico de esta metodología, sino que son propios de la intervención social en general. Sin embargo, vamos a intentar remarcar algunas características importantes que debe tener un trabajo de este tipo.
El vínculo es una relación personal intrínseca a la socialización y que los profesionales utilizamos como herramienta de intervención que nos facilita la adherencia que las personas usuarias van desarrollando con el recurso, con el resto de personas usuarias, con los profesionales y con su propio proceso de intervención. Esta vinculación, además, va a dotar al profesional de una serie de herramientas que van a facilitar y mejorar la intervención con la persona usuaria. Por un lado, nos sirve para identificar las necesidades de las personas usuarias. La relación que se establece cuando acompañamos, en muchas ocasiones, nos da una visión global del individuo. Esto cobra especial importancia en dos tipos de situaciones. Por una parte, en aquellas en las que las habilidades de comunicación están dañadas: en estos casos, la cercanía y el vínculo pueden suplir esa carencia. Por otra, cuando las personas están en una situación tan precaria que tienen dificultades para identificar qué desean o necesitan. Finalmente, da un valor extra a nuestro discurso, pudiendo facilitar que la persona perciba como beneficiosas aquellas propuestas que le hacemos.

En muchos momentos, acompañar es ayudar; es que las personas puedan, con nuestra ayuda, aprender o recuperar unas capacidades que, en el momento de la intervención, no están presentes, a través del apoyo en las propias capacidades del profesional. En otros casos, consideramos que acompañar es dirigir. Hay momentos en los que las personas demandan (directa o indirectamente) a los profesionales que las dirijan en su proceso de intervención. Aunque sea el propio usuario quien marque los objetivos de su intervención, durante el proceso hay casos en los que la persona no sabe alcanzar las metas marcadas, o no tiene los medios para ello, por lo que es el profesional quien debe marcar las directrices de la actuación, aunque no de manera autoritaria, sino bidireccional.

Creemos que la dirección la establecen la persona y el profesional a través de la negociación. La buena interrelación de estos conceptos - dirección y negociación-y la efectividad de la intervención pasan por que los profesionales seamos capaces de escuchar lo que la persona nos está pidiendo, y que ésta sea capaz de interiorizar aquellas cosas que sean beneficiosas de nuestro discurso y nuestra intervención.

Los profesionales tenemos la labor de orientar a las personas hacia aquellas cuestiones que, desde nuestro conocimiento, consideramos que van a producir una mejora más significativa en su situación. Los profesionales de los recursos de baja exigencia suelen facilitar esta orientación durante el acompañamiento, y es más efectiva cuando el vínculo es más fuerte.

Todos estos matices que definen el acompañamiento carecen de sentido si perdemos de vista que acompañar es aceptar el ritmo de la persona. Como 
nos comenta Guillermo Ayuso, de Cáritas Bizkaia, un proceso lineal y en escalera no tiene sentido en baja exigencia, pues no debemos perder de vista que es la persona quien va a marcar la evolución de su propio proceso de intervención.

En torno a esto, Marta Pastor (Comisión Antisida de Bizkaia) también se apoya en la idea de que el acompañamiento es una herramienta que devuelve la autonomía de la persona a través del empoderamiento, y sobre todo, se convierte en un medio para mitigar la soledad que sufren las personas en exclusión residencial grave.

Muchos profesionales, como Pilar Maroto (Sortarazi), Toño Pérez (Comedor de Irala), Josean Macarro (Goiztiri) o Marisa Sevilla (Goiztiri), nos aportan una dimensión del acompañamiento basada en el estar: encontrarse presentes para la persona, sin otro fin, sin marcarnos objetivos de trabajo que supongan una intervención en escalera.

\subsubsection{La labor profesional en la intervención en baja exigencia.}

Las personas que trabajamos en intervención social fundamentalmente tenemos dos funciones: una hace referencia a aquello que tiene que ver con nuestra técnica, manera de trabajar y perfil profesional; la otra, con nuestra competencia emocional, con cómo somos y cómo nos encontramos con la persona a la que acompañamos. Dicho encuentro entre el profesional y la persona usuaria no tiene un único sentido: es bidireccional. Es clave para los profesionales conocer que existe esta influencia mutua, aceptarla, y saber manejarla de modo que genere el mayor beneficio posible.

La función principal que, según Txema Duque, tenemos los profesionales de la intervención en baja exigencia es esforzarnos en tratar de poner los elementos suficientes que den horizonte a la persona. Porque lo fundamental para pasar de una situación a otra es que la persona desee algo. Si no ve cuáles son las posibilidades y variables que le esperan y por las que puede optar, no va a ser capaz de dar ningún paso. Todo esto es un camino de madurez y de crecimiento personal.

Cualquier proceso de intervención pasa por que los profesionales seamos capaces de detectar aquellas necesidades que la persona tiene y quiere satisfacer, pero sobre todo, por ser conscientes de la jerarquía entre ellas. Para ello, durante todo el itinerario, se van a producir negociaciones constantes, en las cuales deberá haber cesiones por ambas partes. Debemos buscar el consenso, siendo firmes con los planteamientos que mutuamente establecemos, respetando, en definitiva, que es la propia persona la que tiene la capacidad y la libertad última de decidir sobre su propia vida. Simultáneamente, debemos hacer que la persona tenga claro que, aunque somos flexibles, en la negociación de la intervención existen límites y, por laxos y pequeños que sean, debemos estar seguros de ellos.

Pero en ocasiones, vamos a tener que delegar la priorización de objetivos en la persona, y ello nos puede producir frustración. En ese sentido, Amaia Porres y Rakel Santurde manifiestan que se trata de un sentimiento diario para los profesionales que trabajamos en este sector, y se deriva, entre otras cosas, del hecho de que somos personas e invertimos esfuerzo e implicación en nuestro trabajo. Convivir con esa frustración pasa por tomar conciencia y aceptar la situación de las personas con las que trabajamos, y las limitaciones tanto propias como de la intervención que realizamos. Tenemos que trabajar para aceptarlo como parte normal del proceso.

Una idea que ha ido saliendo durante las sesiones con los agentes externos y sobre la cual hay consenso es que el trabajo en baja exigencia es de muy alta exigencia para los profesionales. La implicación del profesional, la firmeza, la flexibilidad: gestionar todas estas cuestiones con uno mismo, con el equipo de profesionales y con la entidad requiere un trabajo personal y profesional muy grande. Por ello, Álvaro Ortiz de Zarate destaca la importancia de la formación continua y del soporte emocional dentro de los equipos educativos que intervienen en baja exigencia, sobre todo, con el fin de no olvidar aquellos principios desde los que consideramos que se debe trabajar y que, en ocasiones, podemos perder de vista.

Otro aspecto importante es que los profesionales de baja exigencia deben tener una coordinación constante con los diferentes equipos profesionales que trabajan con las personas que están vinculadas a ellos. Existen multitud de dispositivos para cubrir distintas necesidades, y pocas veces estas atenciones están centralizadas en uno de ellos. Por ello, la coordinación se hace esencial para el mantenimiento de las personas usuarias dentro del itinerario de atención. Éste es un trabajo necesario, que, como comenta Marta Pastor, a veces presenta carencias que derivan en una falta de comunicación entre los profesionales de las diferentes entidades.

\subsubsection{El fin de los procesos de baja exigencia y los límites de estos recursos}

En algunas ocasiones, a los profesionales les resulta fácil discernir cuándo un proceso de intervención en baja exigencia debe terminar. Son aquellos casos en las que la desestructuración con la que la persona accede al recurso es coyuntural. Es decir, posee una serie de capacidades personales suficientes para realizar una vida autónoma, pero, por una situación concreta, necesita, en un momento dado, la atención y contención de baja exigencia. Una vez que vuelve a sus niveles normales de autonomía y está preparada para avanzar en su proceso, la labor de los profesionales de ese ámbito termina. 
Otro de los casos que se antoja claro es aquel en el que la persona decide iniciar un proceso concreto, por ejemplo, un tratamiento de deshabituación en drogodependencias. La intervención de los profesionales de baja exigencia será la de derivar a la persona y finalizar el proceso con ella. El problema se plantea cuando la persona usuaria presenta un nivel alto de desestructuración y una cronicidad en el sistema y en la situación de exclusión social grave; cuando tiene muy mermadas las habilidades personales y sociales. La cronicidad en el perfil de personas a las que atienden los recursos de baja exigencia es una característica bastante común, que lleva a muchas personas a acceder periódicamente a los mismos dispositivos. Esto hace que, para algunos profesionales, sea muy complicado cerrar procesos e intervenciones, puesto que, a menudo, estas personas salen de un servicio de baja exigencia, pero acceden a otro de las mismas características, aunque con distinta finalidad.

Hay servicios de acompañamiento comunitario, como por ejemplo, los equipos de calle, en los cuales resulta difícil decidir cuándo termina el proceso de apoyo a una persona, especialmente a aquellas que siempre van a necesitar apoyo, que presentan múltiples idas y vueltas, y para las que mantener cierto contacto permanente con algunos profesionales les puede ayudar a remontar antes.

Otro aspecto que puede dificultar el cierre de los procesos tiene que ver con los profesionales. Es bastante común sentir (más que pensar) que las personas van a estar desamparadas una vez que finalice nuestra relación con ellas. Toda persona, cuando avanza, lo hace asumiendo ciertos riesgos. Para facilitar la mejora, y hacerlo de una manera sensata, es importante distinguir, no confundir dichos riesgos (consustanciales al movimiento) con sensaciones de peligro no justificadas.

Hay quienes, por sus características personales, van a necesitar apoyo de baja exigencia a lo largo de amplios periodos de su vida. Para tales situaciones, es preciso generar dispositivos, tanto residenciales como diurnos, que puedan acoger a las personas de manera digna y duradera.

\subsubsection{La temporalidad desde la perspectiva de la baja exigencia}

Históricamente, los recursos de baja exigencia, sobre todos aquellos que cubren las necesidades de alojamiento y cobertura nocturna, se han configurado como servicios de temporalidad corta, debido a que tratan de dar respuesta a las necesidades de las personas que no han podido adecuarse a servicios con un tipo de exigencia más alta, sobre todo desde la perspectiva de la urgencia. Las instituciones públicas y las entidades han entendido que estas personas debían pasar pronto a otro tipo de dispositivos que permitieran una estancia más prolongada.
Los servicios configurados como de baja exigencia mantienen actualmente un volumen alto de personas usuarias que permanecen meses o años dentro del dispositivo. Normalmente, esto se debe a que no consiguen mantenerse en otro tipo de servicios, a que se rompen en muchas ocasiones los procesos de intervención iniciados y vuelven así a la situación de sinhogarismo, o al recurso de baja exigencia del que habían salido.

Por lo tanto, podemos concluir que la baja exigencia no debe estar supeditada a una temporalidad corta. En torno a esta cuestión, Guillermo Ayuso y Jon Garmendia, entre otros, son de la opinión de que en los recursos de baja exigencia el criterio del tiempo pierde sentido, ganándolo el discurso del proceso y de la necesidad que tiene la persona. Si aceptamos como principales herramientas de intervención el acompañamiento y el vínculo, acompañar en baja exigencia es aceptar el ritmo de la persona, por lo que los plazos, en muchas ocasiones, pueden dejar de tener sentido.

\section{Factores clave de éxito en baja exigencia}

La mayoría de las ideas que vamos a exponer en este apartado se han explicado a lo largo del artículo. Nuestro objetivo al destacarlas aquí es remarcar la especial importancia que entendemos que tienen para la configuración de una atención de baja exigencia útil, eficiente y sostenible. Así, consideramos que existen siete factores clave en la intervención de baja exigencia:

- Carácter multidimensional del concepto de baja exigencia. No es una metodología de intervención, ni una cultura de atención, ni un perfil de persona usuaria, ni un modo de configurar unos dispositivos: es todas esas cosas a la vez. La clave es que los agentes que intervienen sean capaces de manejar de manera adecuada la relación dinámica entre todos estos elementos.

- Proximidad y accesibilidad: es fundamental que las personas que necesitan una atención de baja exigencia puedan acceder a ella de manera sencilla e inmediata. Es decir, sin trámites que dificulten su entrada a los dispositivos. Y sin tener que buscarlos, lo que produce un efecto por el cual son los servicios los que se acercan a ellos, y no al revés.

- Garantía de supervivencia: la baja exigencia está especialmente indicada para atender situaciones en las que la supervivencia (o una situación de bienestar básico) de la persona puede verse comprometida. Son lo mínimo que debe garantizarse, cubriendo necesidades básicas, y trabajando de manera especial la reducción de daños y la prevención de riesgos.

- Acompañamiento social a través del vínculo: no es específico de la baja exigencia, sino que se da en todo proceso de intervención con personas en exclusión. Sin embargo, es tan importante que no podemos dejar de destacarlo aquí. 
- No contraprestación: las personas tienen derecho a la atención en baja exigencia, sin que nadie deba obligarles a hacer nada a cambio de las prestaciones que reciben. Por otro lado, es obligación del profesional motivar para que aparezca el deseo de cambio de las personas que atiende. $Y$ ambas cosas hay que hacerlas tanto tiempo como sea necesario, sin plazos, que ya suponen una obligación en sí mismos.

- Integración en el entorno: los dispositivos deben tener un carácter comunitario. Primero, por su ubicación física, situándose en donde viven las personas. También, por su implicación en el barrio, que se consigue tomando parte en y apoyando las dinámicas vecinales que se desarrollan allí. Y por último, por su apertura a la ciudadanía, que debe tener el objetivo de crear una visión positiva por parte de ésta.

- Pedagogía social de los responsables públicos: éste es un aspecto que apenas hemos desarrollado en el resto del artículo, pero que es clave. La atención en baja exigencia sólo puede sobrevivir si está legitimada por parte de la sociedad. Y en un momento en el que el ciudadano medio no ve con buenos ojos la presencia de estos dispositivos cerca de su casa, se hace especialmente necesaria la labor pedagógica de los responsables públicos, defendiéndolos sin fisuras.

\section{Agradecimientos}

Este trabajo ha sido posible gracias a mucha gente que ha estado muy cerca de nosotros. Queremos agradecer especialmente:

- A las personas usuarias de los servicios, que son las que, con el paso de los años, nos han ido enseñando buena parte de lo que sabemos y sentimos en nuestro trabajo diario.

- A las personas (trabajadoras, voluntarias, socias) de Bizitegi, que llevan trabajando desde 1999 para atender a quienes lo han perdido casi todo, y que, con su esfuerzo diario y su implicación, dan sentido a todo esto.

- Al equipo de Bizitegi que trabaja actualmente para las personas sin hogar, por el esfuerzo de reflexión que ha realizado durante estas semanas.

- Al resto de las personas de la asociación que, desde otra posición, han apoyado este trabajo, creando el marco que lo hace posible y facilitando la labor de los anteriores.

- A las instituciones públicas, especialmente el Ayuntamiento de Bilbao, por su apuesta por atender a estas personas y su apoyo constante.

- A todas las organizaciones y personas amigas, porque hemos hecho mucha parte de este camino juntas.

- A las personas que, con su experiencia y saber, nos han dado el contraste que necesitábamos: Álvaro Ortiz de Zárate (T4), Amaia Porres (Lagun Artean), Ander Zugaza (Etorkintza), Guillermo Ayuso (Cáritas Bizkaia), Jon Garmendia (Zubietxe), José Bosque (Etorkintza), Josean Macarro (Goiztiri), Joseba Gaya (Cáritas Bizkaia), Mariasun Garay (Red de Salud Mental de Bizkaia), Marisa Sevilla (Goiztiri), Marta Pastor (Comisión Antisida de Bizkaia), Pilar Maroto (Sortarazi), Rakel Santurde (Servicio Municipal de Urgencias Sociales de Bilbao), Toño Pérez (Comedor de Irala) y Txema Duque (Ayuntamiento de Bilbao).

- Al SIIS Centro de Documentación y Estudios, por implicarse activamente en el estudio de la situación de las personas sin hogar, y por la edición de este trabajo. 


\section{Bibliografía}

ARARTEKO (2006): Respuesta a las necesidades básicas de las personas sin hogar / Etxerik gabe eta basterkeria larrian dauden pertsonen premiei emandako erantzuna, Vitoria-Gasteiz, Ararteko.

ÁREA DE ACCIÓN SOCIAL (2015): Memoria 2014, Bilbao, Ayuntamiento de Bilbao / Bilboko Udala.

ASOCIACIÓN BIZITEGI (2010): Modelo de acompañamiento, Bilbao, Asociación Bizitegi.

CONSEJO DE EUROPA (1961): Carta Social Europea [«https:// www.coe.int/en/web/conventions/full-list/-/ conventions/treaty/035>].

DEPARTAMENTO DE EMPLEO Y ASUNTOS SOCIALES (2011): Plan Estratégico de Servicios Sociales de la CAPV 2011-2014 / Gizarte Zerbitzuen Plan Estrategikoa 2011-2014, Vitoria-Gasteiz, Eusko Jaurlaritza-Gobierno Vasco.

- (2012a): Instrumento Técnico Común de Valoración de la Exclusión Social, Vitoria Gasteiz, Eusko Jaurlaritza-Gobierno Vasco [<http://www. gizartelan.ejgv.euskadi.eus/contenidos/ informacion/instrumento_valoracion/ es_instrume/adjuntos/Instrumento $\% 20$ valoracion $\% 20$ exclusion $\% 20$ social-junio\%20 2012.pdf $\rangle$.

- (2012b): Modelo de diagnóstico social, Vitoria-Gasteiz, Eusko Jaurlaritza-Gobierno Vasco [<http:// www.gizartelan.ejgv.euskadi.eus/contenidos/ informacion/instrumento_valoracion/ es_instrume/adjuntos/Modelo $\% 20$ diagnostico\%20social-junio-2012.pdf〉].

DUQUE, T. (2014): “Políticas de servicios sociales para la atención a personas en situación de exclusión residencial grave. Elementos para un diagnóstico y propuestas estratégicas", Zerbitzuan, n-0 55, págs. 35-46 [<http://dx.doi. org/10.5569/1134-7147.55.03>].
- (2012): "Redescubrimiento de los servicios sociales de atención primaria: hacia un (nuevo) modelo de atención personal y comunitaria", Zerbitzuan, nํ52, págs. 23-44 ['http://dx.doi. org/10.5569/1134-7147.52.02>].

DUQUE, T.; ESTOMBA, I.; y AGIRRE, J. (2011): “Acción social municipal en situaciones de urgencia y emergencia social. Experiencia de las capitales de la CAPV", Zerbitzuan, nํ4, págs. 71-80 [khttp://dx.doi.org/ doi:10.5569/1134-7147.49.06)].

FEANTSA (s/d): ETHOS Typology on Homelessness and Housing Exclusión, Bruselas, Federación Europea de Organizaciones Nacionales que trabajan con Personas sin Hogar [«http://www. feantsa.org/spip.php?rubrique175\&lang=en〉].

GARAY, M. et al. (2012): “Evolución del Programa de Asistencia Psiquiátrica a Personas Sin Hogar con Enfermedad Mental Grave en el municipio de Bilbao", Zerbitzuan, ํㅜ 52, págs. 179-190 [rhttp://dx.doi. org/10.5569/1134-7147.52.12>].

GRUPO DE TRABAJO INTER-ÁREAS PARA SITUACIONES DE GRAVE EXCLUSIÓN (2004): Propuesta de actuación con personas sin techo en el municipio de Bilbao, Bilbao, Ayuntamiento de Bilbao, Área de Acción Social.

GRUPO DE TRABAJO ONARTU (2011): Informe técnico sobre la situación de las personas sin hogar y los recursos de ámbito municipal y foral, Bilbao, Ayuntamiento de Bilbao, Área de Acción Social.

NOTARIO, E. et al. (2013): “Programa de media estancia para personas en situación de grave exclusión con necesidades de convalecencia", Zerbitzuan, $\mathrm{n}^{0}$ 53, págs. 83-89 ['http://dx.doi. org/10.5569/1134-7147.53.06)]. 
ONU (1989-2016): Observaciones Generales del Comité de Derechos Económicos, Sociales y Culturales [khttp://tbinternet.ohchr.org/_layouts/ treatybodyexternal/TBSearch.aspx?Lang=en\&Tr eaty $\mid \mathrm{D}=9 \&$ DocTypelD=11>].

- (1966): Pacto Internacional de Derechos Económicos, Sociales y Culturales.

- (1948): Declaración Universal de los Derechos Humanos [«http://www.un.org/es/documents/udhr/ index_print.shtml $]$.

PAÍS VASCO (2015): “Decreto 185/2015, de 6 de octubre, de Cartera de Prestaciones y Servicios del Sistema Vasco de Servicios Sociales", Boletín Oficial del País Vasco, ํㅜ 206, 29-10-15, págs. 1-87 [<https://www.euskadi.eus/y22-bopv/es/ bopv2/datos/2015/10/1504561a.shtml>].

- (2013): “Decreto 353/2013, de 28 de mayo, de Ficha Social del Sistema Vasco de Servicios Sociales y del Instrumento de Diagnóstico Social del Sistema Vasco de Servicios Sociales", Boletín Oficial del País Vasco, no 121, 26-6-13 [<https:// www.euskadi.eus/y22-bopv/es/bopv2/ datos/2013/06/1302907a.shtml>].

- (2008): "Ley 12/2008, de 5 de diciembre, de Servicios Sociales", Boletín Oficial del País Vasco, no 246, 24-12-08, págs. 31.840-31.924 [rhttps://www.euskadi.eus/y22-bopv/es/ bopv2/datos/2008/12/0807143a.shtml/].

SIIS CENTRO DE DOCUMENTACIÓN Y ESTUDIOS (2015): II Estudio sobre la situación de las personas en situación de exclusión residencial grave en la CAPV / EAEn bizitegi-bazterketa larrian daudenen egoerari buruzko II. Azterketa. Donostia-San Sebastián, SIIS Centro de Documentacion y Estudios.
- (2013): "Cuantificación y caracterización de la exclusión residencial en las capitales de la CAPV", Zerbitzuan, no 54 , págs. 97-110 [<http://dx.doi. org/10.5569/1134-7147.54.06)].

UNIÓN EUROPEA (2004): “Tratado por el que se establece una Constitución para Europa", Diario Oficial de la Unión Europea, $\mathrm{n}^{\circ} \mathrm{C}$ 310, 16-12-04, págs. 3-474 [shttp://eur-lex.europa.eu/legalcontent/ES/TXT/?uri=CELEX:12004V/TXT>].

- (2000): "Carta de los Derechos Fundamentales de la Unión Europea”, Diario Oficial de la Unión Europea, $\mathrm{n}^{\circ} \mathrm{C}$ 083, 30-3-10, págs. 389-403 ['http://eur-lex.europa.eu/legal-content/ES/ TXT/?uri=CELEX:12010P/TXT>].

- (1997): "Tratado de Ámsterdam", Diario Oficial de la Unión Europea, $\mathrm{n}^{\circ} \mathrm{C}$ 340, 10-11-97, págs. 1-144 [`http://eur-lex.europa.eu/legal-content/ES/ TXT/?uri=CELEX:11997D/TXT>].

- (1992a): “Recomendación 92/441 del Consejo, de 24 de junio de 1992, sobre los criterios comunes relativos a recursos y prestaciones suficientes en los sistemas de protección social”, Diario Oficial de la Unión Europea, $\mathrm{n}^{\circ} \mathrm{L}$ 245, 26-8-92, págs. 46-48 [<http://eur-lex.europa.eu/legalcontent/ES/TXT/?qid=1460879647575\&uri=CEL EX:31992Ho441>].

- (1992b): “Tratado de la Unión Europea”, Diario Oficial de la Unión Europea, $\mathrm{n}^{\circ} \mathrm{C}$ 191, 29-7-92 [<http://eur-lex.europa.eu/legal-content/ES/ TXT/?uri=0J:C:1992:191:TOC>].

ZABALETA, G. (2012): "Derecho y activación: dos claves de evolución”, Cuadernos de Trabajo Social, vol. 25, n- 1, págs. 87-101. 